\title{
The Effects of Grazing Systems on Plant Communities in Steppe Lands-A Case Study from Mongolia's Pastoralists and Inner Mongolian Settlement Areas
}

\author{
Yintai Na ${ }^{1,2}$, Saixiyalt Bao ${ }^{3}$, Kanji Hashimoto ${ }^{1}$, Christopher McCarthy ${ }^{4}$ and Buho Hoshino ${ }^{1, *}$ (D) \\ 1 Graduate School of Dairy Sciences, Rakuno Gakuen University, Ebetsu, Hokkaido 069-8501, Japan; \\ nayantai201504@gmail.com (Y.N.); kanji14134@gmail.com (K.H.) \\ 2 Resources and Environment Economy College, Inner Mongolia University of Finance and Economics, 185, \\ North Two Ring Road, Hohhot 010070, Inner Mongolia, China \\ 3 College of Geographical Sciences, Inner Mongolia Normal University, No. 81, Zhao Wuda Road, \\ Hohhot 010022, Inner Mongolia, China; baosaixialt@163.com \\ 4 Graduate School of Global Environmental Studies, Kyoto University, Kyoto 606-8501, Japan; \\ mccarthy.ch@gmail.com \\ * Correspondence: aosier@rakuno.ac.jp; Tel.: +81-011-388-4913
}

Received: 6 November 2017; Accepted: 17 January 2018; Published: 18 January 2018

\begin{abstract}
This study examines the effects of different grazing systems in two neighboring regions with similar biotic and abiotic factors, Nalan Soum in Mongolia and Naren Soum in Inner Mongolia, China. We employed the quadrat sampling method and remote sensing to set three perpendicular lines that dissect the boundary between the two countries, and seven lines parallel to the boundary to form a rectangular shape as a means to compare plant community response to different grazing systems under natural conditions. NDVI data is included in discussing the causes of Mongolian grassland degradation. The results of quadrat sampling and NDVI analysis show that rotational grazing has greater values for the quadrat's average height, total coverage, total individual density, and total aboveground biomass $(p<0.05)$, but has lower species richness than continuous grazing $(p>0.05)$. The NVDI values of rotational grazing in 1989, 2005, 2011, and 2016 were higher those of continuous grazing, and significant difference was shown in 2011 and 2016; the NDVI value of continuous grazing in 1993 was higher than that of rotational grazing, but did not show a significant difference. This indicates that different grazing approaches affect steppe ecological systems in different ways, despite their similar biotic and abiotic factors, as well as grazing intensity. Nonetheless, we find rotational grazing to be better for ecosystem vitality than continuous grazing, to some degree.
\end{abstract}

Keywords: rotational grazing; continuous grazing; grassland degradation; case study of nomadic and settlement grazing system; remote sensing; Mongolian grassland

\section{Introduction}

Grazing is the main utilization of the Mongolian grassland. Therefore, the study of grazing effects on the plant community of grasslands has become the focal point in grazing ecology [1,2]. Currently, together with climate change, grazing has gradually increased the degradation of the Mongolian steppe. In addition, the implementation of China's Pasture Household Contract Responsibility System policy has further accelerated degradation. Grassland degradation has also resulted in an imbalance of grassland ecology, leading to the efficiency of grassland ecosystem services being greatly reduced [3,4]. Recently, precision grazing management systems have become a hot research topic for grazing ecologists throughout the world. Both rotational grazing and continuous grazing have also become focal points, whereby their pros and cons are discussed through controlled experiments [5-7]. 
Though controlled experiments offer reliable results, in grazing studies, they suffer from a number of shortcomings: (1) controlled experiments are usually done during the growing season, and seldom consider the effects of grazing throughout the year; (2) experiments usually involve only one type of livestock, and lack the consideration of the combined effects of several livestock species; (3) studies often include only a limited area, with a short time span; (4) experiments provide only a simple control of grazing and rest-grazing time, without taking into account the effective control of pastoralists according to climatic and grassland conditions.

Both Mongolia and Inner Mongolia share the Mongolian grasslands. In earlier times, the same grazing system was employed throughout the region; but after 1990, different grazing systems were developed on each side of the border-i.e., rotational grazing (RG) in Mongolia, continuous grazing (CG) in Inner Mongolia, and forbidden grazing (FG) near the boundary region-which have changed or disturbed the plant communities of the grassland in different ways. Therefore, the boundary region of China and Mongolia is the best location to study the differences between the effects of the different types of grazing systems toward the same grassland ecosystem [8]. Yet, factors including the fact that the region is large and is managed by two different countries, as well as communication issues, difficult accessibility, etc., have prevented many scholars from studying the grassland as a whole. Therefore, most scholars have only carried out experimental studies on a smaller area to understand the differences between the effects of different grazing systems on the plant community, instead of carrying out the study directly on-site within a larger area. In addition, few studies have integrated multiple methods such as remote sensing, the quadrat sampling method, the belt transect sampling method, plant community and regional geography, which also represent heaven, earth, nature and society, in realizing quantitative analysis. We utilized quadrat and belt sampling methods, and remote sensing to survey the changes to plant communities over a period of 28 years (1989-2016) by setting up three lines perpendicular to the border of China and Mongolia, and seven lines parallel to the boundary, forming a rectangular region of about $1400 \mathrm{~km}^{2}$. With sufficient consideration regarding the postulation of the intensity effect caused by pastoral management and grazing from the point when the grazing systems changed in 1990, (1) we compared the differences between the effects of different grazing systems on plant communities under relatively natural conditions; (2) we also discuss the causes of degradation on the Mongolian grassland in order to ensure a sustainable grassland ecosystem based on a scientific basis in the future.

\section{Materials and Methods}

\subsection{Study Area}

The study region is typical steppe land, located at the boundary region of Inner Mongolia, China and Mongolia. The study site is divided into two areas, Nalan Soum of Mongolia and Naren Soum of Inner Mongolia. Both areas are utilized purely as grazing land, basically have the same vegetation types, weather, topography, soil, production method (grazing) and stocking rate. The soil is made up of chestnut soil with a humus layer 5-10 cm thick; average annual rainfall from 1971 to 2016 was $220.6 \pm 65.2 \mathrm{~mm}$, whereby $60 \%$ to $80 \%$ of rain fell during the growing season (July to September) and the evaporation rate was $1505 \pm 45.4 \mathrm{~mm}$. The structural species are feathergrass (Stipa grandis) and Chinese rye grass (Leymus chinensis), while the dominant species are needle leaf sedge (Carex duriuscula), needle grass (Stipa krylovii), prairie sagewort (Artemisia frigida), Chenopodium acuminatum, Cleistogenes squarrosa, Allium polyrhizum, etc. (Figure 1 and Table 1). 


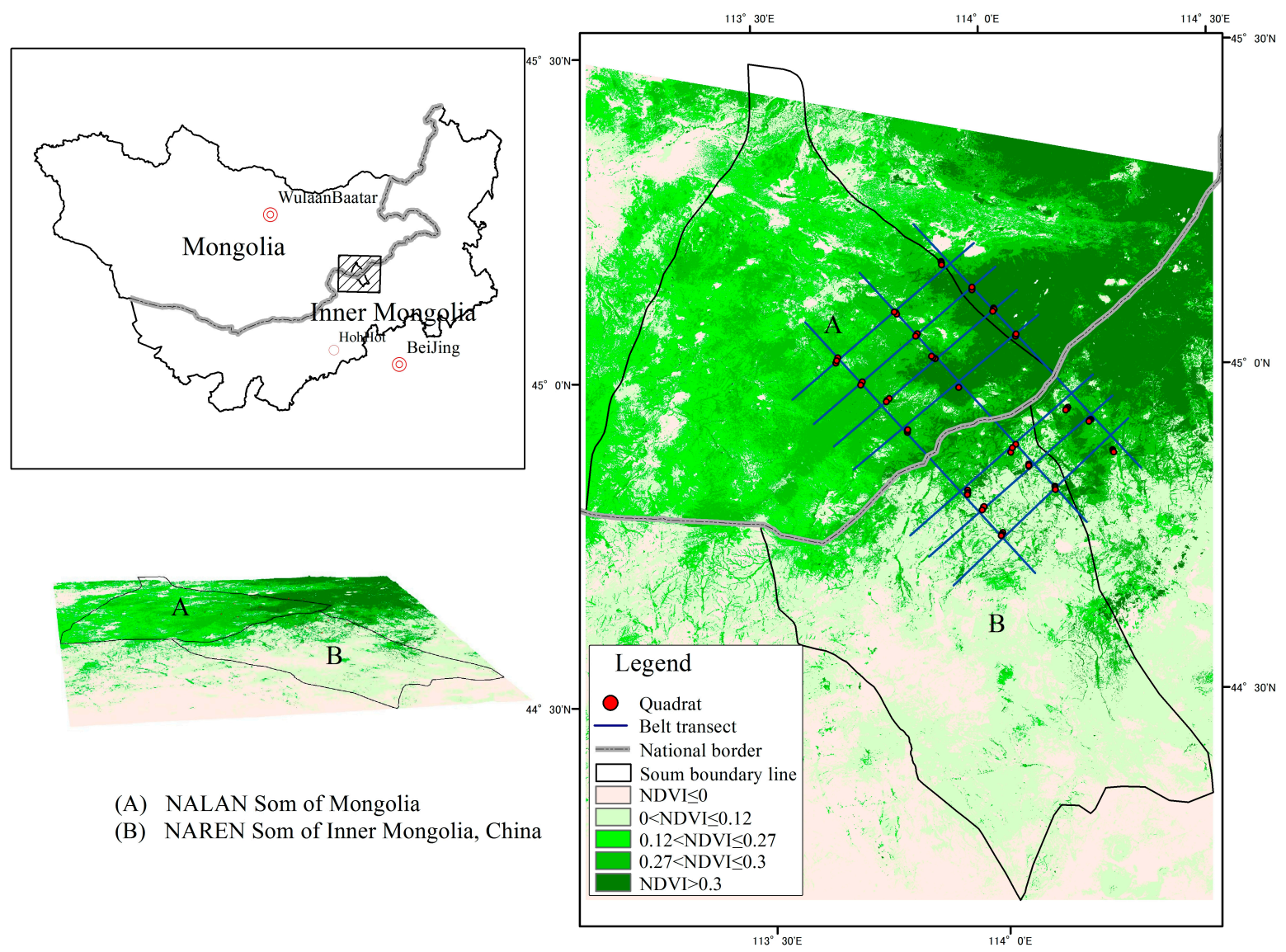

Figure 1. Study area and quadrat distribution.

Table 1. Result of ecological factors in study area.

\begin{tabular}{ccc}
\hline & Nalan Soum & Naren Soum \\
\hline Annual mean temperature $\left({ }^{\circ} \mathrm{C}\right)$ & $1.41 \mathrm{a}$ & $1.03 \mathrm{a}$ \\
Annual total precipitation $(\mathrm{mm})$ & $216.80 \mathrm{a}$ & $224.49 \mathrm{a}$ \\
Altitude $(\mathrm{m})$ & $1356.21 \mathrm{a}$ & $1346.39 \mathrm{a}$ \\
Average annual evaporation $(\mathrm{mm} / \mathrm{y})$ & $1505.14 \mathrm{a}$ & $1498.52 \mathrm{a}$ \\
Average stocking rate (sheep unit $\left./ \mathrm{km}^{2}\right)$ & $42 \mathrm{a}$ & $50 \mathrm{a}$ \\
Soil type & Chestnut soil & Chestnut soil \\
Soil humidity (VWC) & $7.5 \% \mathrm{a}$ & $6.9 \% \mathrm{~b}$ \\
\hline
\end{tabular}

Note: The lowercase letters indicate the significant difference at $5 \%$ level; Source: Meteorological Bureu of Xilingol League and National Agency for Meteorology and Environmental Monitoring of Mongolia.

Stocking rate $=$ the total number of livestock (sheep units) owned by the herder where the quadrat is located/the total area of the grassland owned by the herder. Livestock data and grassland area were obtained from annual statistics data, and then verified via on-site survey and local community interviews, for which all types of livestock were converted to sheep units according to China's sheep unit conversion standard as follows: 1 camel $=7$ sheep, 1 horse $=6$ sheep, 1 cow $=5$ sheep and 1 goat $=1$ sheep.

\subsection{Grazing Systems of Inner Mongolia (China) and Mongolia}

Mongolians mainly live in Mongolia and Inner Mongolia, and are mainly herders of "five livestock", i.e., sheep, goats, cows, horses and camels. Because of the historical background, Mongolia and Inner Mongolia were divided into two different countries from the early 19th century. 
Since then, the two countries have employed two different grazing systems, whereby Mongolia maintained original nomadic grazing strategies (rotational grazing) and China introduced a continuous grazing system. Especially when China's Pasture Household Contract Responsibility System policy was implemented in 1990, herders began to fence their pasture land and graze their animals only at fixed locations (Table 2).

Table 2. Changes of Mongolia and China grazing systems.

\begin{tabular}{ccccc}
\hline \multirow{2}{*}{ Country } & \multicolumn{2}{c}{ Mongolia } & \multicolumn{2}{c}{ Inner Mongolia } \\
\cline { 2 - 5 } Time & $\mathbf{1 9 5 8 - 1 9 9 0}$ & $\mathbf{1 9 9 0 - T o d a y}$ & $\mathbf{1 9 7 8 - 1 9 9 0}$ & 1990-Today \\
\hline Livestock Ownership & Common & Private & Private & Private \\
Pasture Ownership & Common & Common & Common & Private \\
Grazing Method & Rotational & Rotational & Rotational & Continuous \\
& Grazing & Grazing & Grazing & Grazing \\
\hline
\end{tabular}

The Pasture Household Contract Responsibility System implemented in Inner Mongolia is a centrally designated policy that allocates pasture land to villages based on population size, livestock amount, grassland quality, grazing habits, etc. Pasture land is contracted to villagers by village committees for a period of 50 years. Meanwhile, herders in Mongolia carry out rotational grazing depending on grassland conditions and seasonal change and usually rotate once per two to three seasons [9].

\subsection{Field Sampling and Data Collection}

As the topography characteristics of the Mongolian grasslands are flat with larger ecological niches and continuous landscape, two study locations at the boundary region of Inner Mongolia and Mongolia known as "soum" were chosen, one at each side along the boundary, which have similar biotic and abiotic conditions. By using the principles of quadrat and belt transect sampling methods, three lines perpendicular to the boundary at each side and seven lines parallel with boundary that went across the three perpendicular lines to form rectangular shapes were established with the help of Google Earth and GPS. The length of each perpendicular line cutting across both Mongolia and Inner Mongolia was $40 \mathrm{~km}$, while the length of each parallel line was $20 \mathrm{~km}$, of which four of the lines were located in Mongolia and other three lines were located in Inner Mongolia. Among the four parallel lines located within Mongolia, one was set at the forbidden grazing area, located $5 \mathrm{~km}$ away from the border. These three perpendicular lines and seven parallel lines were set up so that their intersection points became the marked points to set up three individual quadrats. In addition, the quadrats had a distance of $150 \mathrm{~m}$ from one another. The field survey was carried out during the peak biomass period, which was from the end of July to mid-August 2016, and a total of 61 quadrats of $1 \mathrm{~m} \times 1 \mathrm{~m}$ each were surveyed. In each quadrat, the number of species, total individual density, total aboveground biomass, total coverage and average height, soil type and humidity were measured and recorded.

Cloudless satellite images from the study locations (126/29), dated 3 August 1989; 15 September 1993; 14 July 2005; 31 July 2011 and 13 August 2016 from Thematic Mapper (TM) and Enhanced Thematic Mapper (ETM) were utilized for the study (http:// earthexplorer.usgs.gov/). The image resolution was $30 \mathrm{~m}$ with Band $3(0.66 \mu \mathrm{m})$ and Band $4(0.84 \mu \mathrm{m})$. From these images, the changes to the plant community in the sampling points were identified through a series of image processing, i.e., geometric correction, atmospheric correction, radiometric calibration, NDVI calculation, clipping and statistical calculation.

In order to obtain an accurate NDVI value, not only were NDVI values for the pixels calculated, but the eight surrounding pixels were also included in the calculation so that the average NDVI value of the nine pixels for the particular quadrat point were obtained. 


\subsection{The Plant Community Characteristics}

The plant community characteristics were identified based on the average height, total coverage, total individual density, species richness $(R)$ and total aboveground biomass [10].

Average height refers to the average taken from three plant height values per quadrat, measured with a measuring tape.

Total coverage refers to the vertical projection of the outermost perimeter of the natural spread of foliage for all plant species found in each quadrat. It was calculated based on the average of three persons' visual measurement results.

Total individual density refers to the total number of individuals of all species per quadrat, calculated via an artificial statistical method.

Total aboveground biomass was calculated by using a destructive method, whereby all plants in each quadrat were harvested, and their fresh weight was measured with a $0.01 \mathrm{~g}$ precision digital scale directly at the field site.

Species richness refers to the number of species per quadrat.

Soil humidity was tested with a portable TDR (@Hydrosense, Made in Australia) a depth of $20 \mathrm{~cm}$.

\subsection{Data Analysis}

Normalized Difference Vegetation Index (NDVI) has a good correlation with vegetation coverage, biomass and biological productivity, and is therefore widely used in the study of regional vegetation coverage and change. Therefore, it is commonly used to show the coverage of arid regions $[11,12]$. Its calculation method is shown below:

$$
\mathrm{NDVI}=\frac{\mathrm{NIR}-\mathrm{RED}}{\mathrm{NIR}+\mathrm{RED}}
$$

where, NIR is the reflectance of the near-infrared (NIR) channel and RED is the reflectance of the red channel.

Statistical calculation of the plant community, weather and livestock data were calculated with Excel 2010 software, while the NDVI calculation of remote sensing data was performed mainly with ENVI 5.0 (CHarris) and ArcGIS 10.0 (CESRI) and R language 3.2 was also used to calculate the randomization test based on the NDVI values and vegetation community data of Mongolia, Inner Mongolia and the boundary region, as well as the ecological factors between Nalan and Naren.

\section{Results}

\subsection{Changes in Plant Community Characteristics in Response to Different Grazing Systems}

Under different grazing systems, plant community average height decreases from forbidden grazing $(21.2 \mathrm{~cm})>$ rotational grazing $(14.8 \mathrm{~cm})>$ continuous grazing $(8.4 \mathrm{~cm})$, with a significant difference among the three systems $(p<0.05)$; total coverage decreases from forbidden grazing $(67.9 \%)>$ rotational grazing $(64.3 \%)>$ continuous grazing $(56.5 \%)$, with a significant difference between rotational grazing and continuous grazing, but not between rotational grazing and forbidden grazing, or between forbidden grazing and continuous grazing; and total aboveground biomass decreases from forbidden grazing $(455.9 \mathrm{~g})>$ rotational grazing $(268.4 \mathrm{~g})>$ continuous grazing $(122.2 \mathrm{~g})$, with a significant difference among the three systems $(p<0.05)$.

Total individual density decreases from rotational grazing $\left(439.4\right.$ individuals $\left./ \mathrm{m}^{2}\right)>$ continuous grazing (310.6 individuals $\left./ \mathrm{m}^{2}\right)>$ forbidden grazing $\left(228.4\right.$ individuals $\left./ \mathrm{m}^{2}\right)$, with significant difference between rotational grazing and forbidden grazing $(p<0.05)$, but not between continuous grazing and forbidden grazing; species richness decreases from continuous grazing $\left(12.5 \mathrm{species} / \mathrm{m}^{2}\right)>$ rotational grazing $\left(12.4\right.$ species $\left./ \mathrm{m}^{2}\right)>$ forbidden grazing $\left(11.4\right.$ species $\left./ \mathrm{m}^{2}\right)$, but there is no significant difference (Figure 2A-E). 

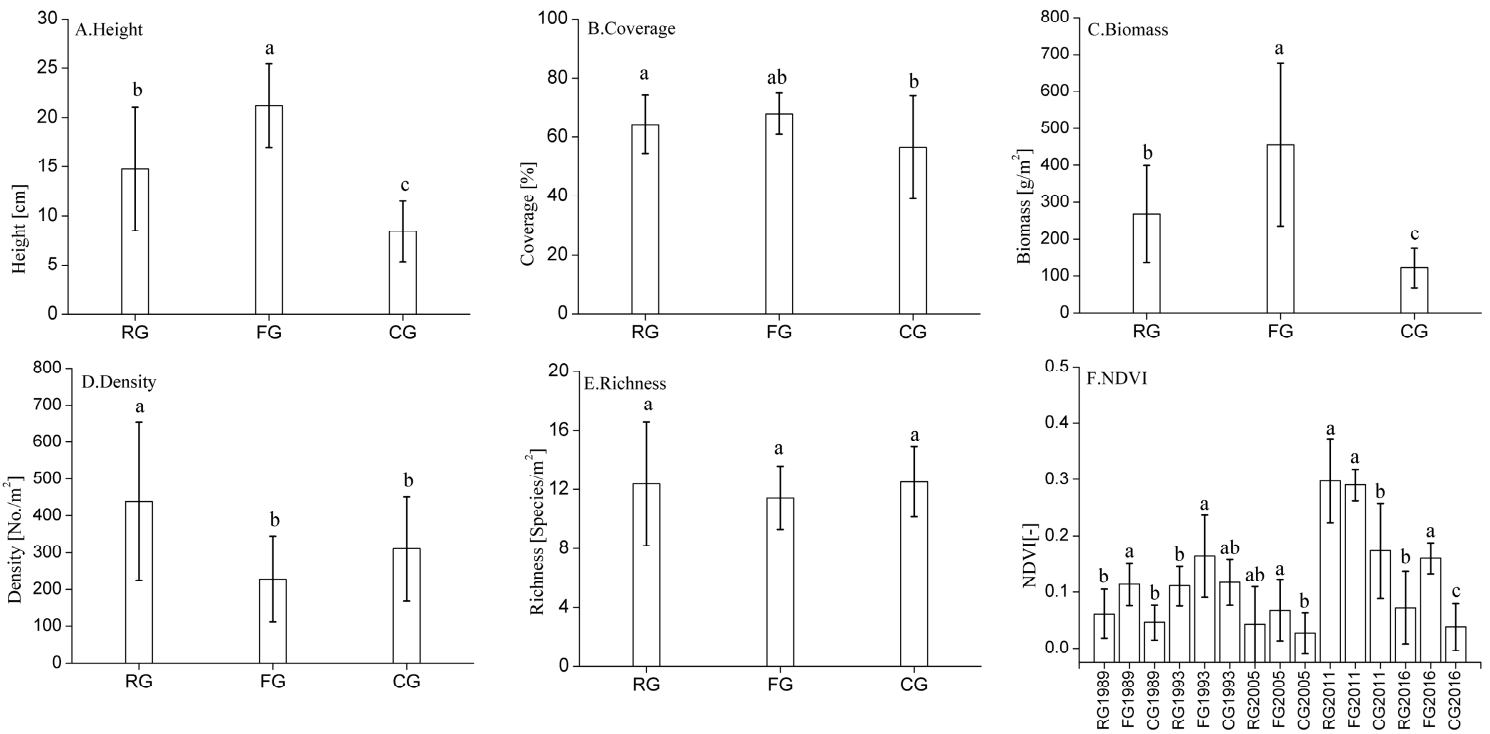

Figure 2. Average height, total coverage, total aboveground biomass, total individual density, species richness and NDVI value of regions with different grazing systems (mean \pm SD). RG (Rotational Grazing); FG (Forbidden Grazing); CG (Continues Grazing) (Where, A-Height; B-Coverage; C-Biomass; D-Density; E-Richness; F-NDVI).

\subsection{Changes in NDVI Value in Response to Different Grazing Systems}

For the five time periods of the NDVI data in Figure $2 \mathrm{~F}$, the NDVI value decreases from forbidden grazing $(0.16)>$ continuous grazing $(0.12)>$ rotational grazing $(0.11)$ in 1993; NDVI value decreases from rotational grazing $(0.3)>$ forbidden grazing $(0.29)>$ continuous grazing $(0.17)$ in 2011; and NDVI value decreases from forbidden grazing > rotational grazing > continuous grazing in 1989, 2005 and 2016, respectively; 1989: 0.11, 0.06, 0.04; 2005: 0.07, 0.04, 0.03; 2016: $0.11,0.06,0.04$. When comparing the NDVI value of continuous grazing and rotational grazing, there is significant difference in 2011 and $2016(p<0.05)$, but not in 1989, 1993 or 2005; when comparing the NDVI value of forbidden grazing and rotational grazing, there is a significant difference in 1989, 1993 and $2016(p<0.05)$, but not in 2005 or 2011. When comparing the NDVI value of forbidden grazing and continuous grazing, there is significant difference in 1989, 2005, 2011 and 2016, but not in 1993.

\section{Discussion}

\subsection{Effects of Different Grazing Systems on Plant Community Characteristics}

Herbivores can directly affect the changes in plant communities and richness because of their feeding behavior $[1,13,14]$.

The results of average height, total coverage and total aboveground biomass of forbidden grazing are larger than both rotational grazing and continuous grazing, of which the average height and total aboveground biomass are significantly greater (Figure $2 \mathrm{~A}-\mathrm{C}$ ), are the same as found in many other studies. This could be primarily due to livestock change and the impact from feeding, trampling, etc., which reduces the surface area for photosynthesis and changes the vegetation structure, thus affecting plant community characteristics $[15,16]$. Previous studies have shown that vegetation within forbidden grazing regions, which are not impacted by feeding and trampling, grow rampantly; hence, the average height, total aboveground biomass and species richness are significantly greater than in the grazing region $[17,18]$. However, some studies have also pointed out that the dominant species in the forbidden grazing region will directly or indirectly control the vitality of other species. Therefore, intense competition between the species will suppress or eliminate other weaker species, and would lower 
the species richness, reduce the number of shorter plants, and eventually reduce the biomass [19-23]. This study shows that the total coverage of forbidden grazing exhibits no significant difference from rotational grazing and continuous grazing; total individual density decreases from rotational grazing > continuous grazing $>$ forbidden grazing; species richness decreases from continuous grazing $>$ rotational grazing $>$ forbidden grazing (Figure 2B,D,E). The above results explain that the average height, total coverage and total aboveground biomass of both rotational grazing and continuous grazing decrease, but the removal of surface and old plant tissues can induce new plant growth by providing larger growing space for weaker species, thus increasing the total individual density and species richness.

Even though the average height and total aboveground biomass of the forbidden grazing region are significantly greater than those found in the grazing region, the cumulative growth of plant height and biomass require compensatory plant growth experiments to determine the advantages of the forbidden grazing and grazing regions. Grazing can have mechanisms to both suppress and enhance plant growth; and the compensatory plant growth is subjected to the net effect of suppressing and enhancing events, whereby the net effect is closely related to the types of plant communities, grazing system, grazing intensity, environmental conditions, etc. [24].

The existence of significant differences in average height, total coverage and total aboveground biomass between rotational grazing and continuous grazing is likely the result of rotational grazing being characterized by the effect of different sensitivities of grasses at different growing stages [25]; human intervention ensures that the ecosystem functions, and that the health of the grassland is maintained above its minimum threshold level by providing a sufficient resting period for regrowth before using the area again [26]. As a result, rotational grazing not only increases grass production, but also increases the stocking rate [27]. The grassland can recover if the degree of damage and richness does not exceed its ecological threshold; otherwise, grassland degradation will take place [28,29].

\subsection{Effects of Different Grazing Systems on Changes in NDVI Value}

NDVI is very sensitive towards the biophysical characteristics of vegetation [30]. As all abiotic factors, such as weather, topography and soil, as well as grazing intensity, are generally the same throughout the region (Table 1), the grazing systems could be the main factor affecting the grassland ecosystem $[8,31]$.

Nalan Soum in Mongolia introduced private ownership of livestock from 1990; however, a rotational grazing system is still the dominant method of livestock management. On the other hand, Inner Mongolia has had a private ownership system since 1978, but the implementation of the Pasture Household Contract Responsibility System in 1990 has gradually replaced the use of the rotational grazing system with the continuous grazing system in Naren Soum (Table 2).

From 1989 to 2016, for a period of 28 years, the average stocking rate of herders at the sampling location in Nalan Soum in Mongolia was 42 sheep per $\mathrm{km}^{2}$, while it was 50 sheep per $\mathrm{km}^{2}$ in Naren Soum in Inner Mongolia, with no significant difference $(p>0.05)$ (Table 1).

Results from the five time periods of NDVI values show that the NDVI value for the continuous grazing region is becoming lower than for the rotational grazing region. Near the end of the 18th century, the theory of rotational grazing was developed by James Anderson in Scotland. After that, many other scholars carried out supporting studies at various locations, showing that rotational grazing can increase grass production and improve grassland utilization [6,7,32]. Some studies also explain that rotational grazing can facilitate grassland recovery, increase vegetation coverage and pasture quality [33]. In particular, choosing a suitable grazing system for different topographic conditions can improve grassland utilization and prevent degradation, as well as being beneficial to livestock production [28]. However, Derek W. Bailey proposed that in arid and semi-arid shrub lands, timely adjustments to animal numbers and practices that improve grazing distribution at regional and landscape scales are more likely to be effective in maintaining or improving rangeland health than fencing and rotational grazing [34]. Martin and his colleagues explain that rotational grazing can 
facilitate grassland recovery when the grassland is unhealthy, but such effects are minimal when the grassland is healthy [27]; Heitschmidt and his team (1987), who chose cows as their target animals in their experiment in Texas, found that the impacts of rotational grazing and continuous grazing on the environment were basically similar, and that the differences are mainly caused by the difference in grazing intensity [5]. In addition, Heitschmidt (1982) also found that different grazing seasons and grazing systems affect vegetation differently [35].

The NDVI changes of forbidden grazing and the other two grazing systems show that forbidden grazing managed to protect the biomass, coverage, etc. of the area for the same reasons as those for the plant community characteristics between forbidden grazing and the other two grazing systems, as described above. The results of the NDVI values show no significant difference between forbidden grazing and rotational grazing in 2005. Even in 2011, in which the NDVI value of rotational grazing was larger than forbidden grazing, it is shown that the NDVI values for the grazing regions can be larger than the forbidden grazing region under certain conditions. For instance, as the rainfall of Nalan Soum $(90 \mathrm{~mm})$ in 2005 was lower than the average rainfall $(216.80 \mathrm{~mm})$, NDVI values of the study area were relatively lower; meanwhile, the NDVI values for rotational grazing and forbidden grazing showed no significant difference. Another example is the rainfall of Nalan Soum $(217.56 \mathrm{~mm})$ in 2011, which was higher than the average rainfall, causing the NDVI values of the study area to be relatively higher; while the NDVI values of rotational grazing were higher than the NDVI values of forbidden grazing, there was no significant difference between them. This result actually supports earlier scholars, who suggested that moderate grazing can increase species richness and biomass. They also pointed out that the species richness and functional diversity are greatest during moderate grazing, and thus it can ensure sustainable use of grassland, as it increases the complexity and stability of the plant community [36,37]. In addition, Collins and Loeser show that long periods of forbidden grazing reduce the species richness and production of plant communities [21,22]. Together with the findings that the total individual density and species richness of forbidden grazing are lower than that of rotational grazing and continuous grazing, these results show that more studies are needed to identify whether forbidden grazing is better for ecosystem health.

\section{Conclusions}

In conclusion, the results of quadrat sampling reflecting current conditions and NDVI changes show that this study's rotational grazing region has greater values for average height, total coverage, total individual density, total aboveground biomass and NDVI for most years, but lower species richness values than the continuous grazing region studied. This indicates that different grazing systems obviously affect steppe ecological systems differently, despite having similar biotic and abiotic factors and grazing intensities. Nonetheless, rotational grazing is better than continuous grazing to some degree. Additionally, because the vegetation type, grazing intensity, grazing time and livestock type are different from other examples and conditions, the effects of the grazing system on plant communities are rather sophisticated. Therefore, more in-depth and holistic research, which integrates spatial differences, population structure, interspecific relationships, etc., is needed in future study.

Acknowledgments: The authors would like to thank the many research students and professors who contributed to this study, including Sorgog, Qinggel, Has and Wuhant from Inner Mongolia Normal University, as well as professors Basarhand and Alantanbater, and research student Yider from The National University of Mongolia. This research was supported by Grants No. 61661045, No. 41561009, No. 41561050 and No. NJZY17158. Additional support was provided by JSPS KAKENHI Grant Numbers JP24340111, JP25550079, JP26281003 and the MEXT Supported Program for the Strategic Research Foundation (S1391001) at Rakuno Gakuen University.

Author Contributions: Yintai Na, Christopher McCarthy and Buho Hoshino analyzed the data and wrote the draft of manuscript and designed the study. Yintai Na, Saixiyalt Bao, and Buho Hoshino participated in the field measurements. Yintai Na, Kanji Hashimoto and Buho Hoshino established the GIS special database and worked on the data analysis and statistical software programing.

Conflicts of Interest: The authors declare no conflict of interest. 


\section{References}

1. Milchunas, D.G.; Sala, O.E.; Lauenroth, W.K. A generalized model of the effects of grazing by large herbivores on grassland community structure. Am. Nat. 1988, 132, 87-106. [CrossRef]

2. Briske, D.D.; Derner, J.D.; Brown, J.R.; Fuhlendorf, S.D.; Teague, W.R.; Havstad, K.M.; Gillen, R.L.; Ash, A.J.; Willms, W.D. Rotational grazing on rangelands: Reconciliation of perception and experimental evidence. Rangel. Ecol. Manag. 2008, 61,3-17. [CrossRef]

3. Conte, T.J.; Tilt, B. The effects of China's grassland contract policy on pastoralists' attitudes towards cooperation in an Inner Mongolian banner. Hum. Ecol. 2014, 42, 837-846. [CrossRef]

4. Han, G.; Hao, X.; Zhao, M.; Wang, M.; Ellert, B.H.; Willms, W.; Wang, M. Effect of grazing intensity on carbon and nitrogen in soil and vegetation in a meadow steppe in Inner Mongolia. Agric. Ecosyst. Environ. 2008, 125, 21-32. [CrossRef]

5. Heitschmidt, R.K.; Dowhower, S.L.; Walker, J.W. Some effects of a rotational grazing treatment on quantity and quality of available forage and amount of ground litter. J. Range Manag. 1987, 40, 318-321. [CrossRef]

6. Derner, J.D.; Gillen, R.L.; McCollum, F.T.; Tate, K.W. Little bluestem tiller defoliation patterns under continuous and rotational grazing. J. Range Manag. 1994, 47, 220-225. [CrossRef]

7. Jacobo, E.J.; Rodríguez, A.M.; Bartoloni, N.; Deregibus, V.A. Rotational grazing effects on rangeland vegetation at a farm scale. Rangel. Ecol. Manag. 2006, 59, 249-257. [CrossRef]

8. Wang, J.; Brown, D.G.; Chen, J. Drivers of the dynamics in net primary productivity across ecological zones on the mongolian plateau. Landsc. Ecol. 2013, 28, 725-739. [CrossRef]

9. Hai, S. Study on the Relationship between Human and Land in Inner Mongolia Pasture; Inner Mongolian Education Press: Hohhot, China, 2013; pp. 131-143.

10. Zhang, J.T. Sampling Methods and Community Characterization, 2nd ed.; Sciences Publisher: Beijing, China, 2011; pp. 9-25.

11. Hoshino, B.; Yonemori, M.; Manayeva, K.; Karamalla, A.; Yoda, K.; Suliman, M.; Elgamri, M.; Nawata, H.; Mori, Y.; Yabuki, S.; et al. Remote sensing methods for the evaluation of the mesquite tree (Prosopis juliflora) environmental adaptation to semi-arid Africa. In Proceedings of the 2011 IEEE International Geoscience and Remote Sensing Symposium, Vancouver, BC, Canada, 24-29 July 2011; pp. 1910-1913.

12. Tucker, C.J. Red and photographic infrared linear combinations for monitoring vegetation. Remote Sens. Environ. 1979, 8, 127-150. [CrossRef]

13. Olff, H.; Ritchie, M.E. Effects of herbivores on grassland plant diversity. Trends Ecol. Evolut. 1998, 13, 261-265. [CrossRef]

14. Metera, E.; Sakowski, T.; Sloniewski, K.; Romanowicz, B. Grazing as a tool to maintain biodiversity of grassland-A review. Anim. Sci. Pap. Rep. 2010, 28, 315-334.

15. Huhta, A.-P.; Hellstrom, K.; Rautio, P.; Tuomi, J. Grazing tolerance of gentianella amarella and other monocarpic herbs: Why is tolerance highest at low damage levels? Plant Ecol. 2003, 166, 49-61. [CrossRef]

16. Carrera, A.L.; Bertiller, M.B.; Larreguy, C. Leaf litterfall, fine-root production, and decomposition in shrublands with different canopy structure induced by grazing in the Patagonian Monte, Argentina. Plant Soil 2008, 311, 39-50. [CrossRef]

17. Firincioglu, H.K.; Seefeldt, S.S.; Sahin, B. The effects of long-term grazing exclosures on range plants in the central Anatolian region of Turkey. Environ. Manag. 2007, 39, 326-337. [CrossRef] [PubMed]

18. Deak, B.; Tothmeresz, B.; Valko, O.; Sudnik-Wojcikowska, B.; Moysiyenko, I.I.; Bragina, T.M.; Apostolova, I.; Dembicz, I.; Bykov, N.I.; Torok, P. Cultural monuments and nature conservation: A review of the role of kurgans in the conservation and restoration of steppe vegetation. Biodivers. Conserv. 2016, 25, 2473-2490. [CrossRef]

19. Brinkert, A.; Hoelzel, N.; Sidorova, T.V.; Kamp, J. Spontaneous steppe restoration on abandoned cropland in Kazakhstan: Grazing affects successional pathways. Biodivers. Conserv. 2016, 25, 2543-2561. [CrossRef]

20. Grime, J.P. Evidence for the existence of 3 primary strategies in plants and its relevance to ecological and evolutionary theory. Am. Nat. 1977, 111, 1169-1194. [CrossRef]

21. Collins, S.L.; Bradford, J.A.; Sims, P.L. Succession and fluctuation in Artemisia dominated grassland. Vegetatio 1988, 73, 89-100. [CrossRef]

22. Loeser, M.R.R.; Sisk, T.D.; Crews, T.E. Impact of grazing intensity during drought in an Arizona grassland. Conserv. Biol. 2007, 21, 87-97. [CrossRef] [PubMed] 
23. Guo, Q.; Berry, W.L. Species richness and biomass: Dissection of the hump-shaped relationships. Ecology 1998, 79, 2555-2559. [CrossRef]

24. Oesterheld, M.; McNaughton, S.J. Effect of stress and time for recovery on the amount of compensatory growth after grazing. Oecologia (Berlin) 1990, 85, 305-313. [CrossRef] [PubMed]

25. Bai, Y.; Han, X.; Wu, J.; Chen, Z.; Li, L. Ecosystem stability and compensatory effects in the Inner Mongolia grassland. Nature 2004, 431, 181-184. [CrossRef] [PubMed]

26. Garcia, C.A.M.; Schellberg, J.; Ewert, F.; Brueser, K.; Canales-Prati, P.; Linstaedter, A.; Oomen, R.J.; Ruppert, J.C.; Perelman, S.B. Response of community-aggregated plant functional traits along grazing gradients: Insights from African semi-arid grasslands. Appl. Veg. Sci. 2014, 17, 470-481. [CrossRef]

27. Martin, S.C.; Severson, K.E. Vegetation response to the Santa Rita grazing system. J. Range Manag. 1988, 41, 291-295. [CrossRef]

28. Hao, J.; Dickhoefer, U.; Lin, L.; Mueller, K.; Glindemann, T.; Schoenbach, P.; Schiborra, A.; Wang, C.; Susenbeth, A. Effects of rotational and continuous grazing on herbage quality, feed intake and performance of sheep on a semi-arid grassland steppe. Arch. Anim. Nutr. 2013, 67, 62-76. [CrossRef] [PubMed]

29. Tilman, D.; Wedin, D.; Knops, J. Productivity and sustainability influenced by biodiversity in grassland ecosystems. Nature 1996, 379, 718-720. [CrossRef]

30. Sternberg, T.; Tsolmon, R.; Middleton, N.; Thomas, D. Tracking desertification on the Mongolian steppe through NDVI and field-survey data. Int. J. Digit. Earth 2011, 4, 50-64. [CrossRef]

31. Zhang, M.A.; Borjigin, E.; Zhang, H. Mongolian nomadic culture and ecological culture: On the ecological reconstruction in the agro-pastoral mosaic zone in northern China. Ecol. Econ. 2007, 62, 19-26. [CrossRef]

32. Michael, H.R.; Kothmann, M.M.; Taylor, C.A. Vegetation response to increased stocking rates in short-duration grazing. J. Range Manag. 1990, 43, 104-108.

33. Savory, A.; Stanley, D.P. The savory grazing method. Rangelands 1980, 2, 234-237.

34. Bailey, D.W.; Brown, J.R. Rotational grazing systems and livestock grazing behavior in shrub-dominated semi-arid and arid rangelands. Rangel. Ecol. Manag. 2011, 64, 1-9. [CrossRef]

35. Heitschmidt, R.K.; Price, D.L.; Gordon, R.A.; Frasure, J.R. Short Duration Grazing at the Texas Experimental Ranch: Effects on Aboveground Net Primary Production and Seasonal Growth Dynamics. J. Range Manag. 1982, 35, 367-372. [CrossRef]

36. McIntyre, S.; Heard, K.M.; Martin, T.G. The relative importance of cattle grazing in subtropical grasslands: Does it reduce or enhance plant biodiversity? J. Appl. Ecol. 2003, 40, 445-457. [CrossRef]

37. Ruifrok, J.L.; Postma, F.; Olff, H.; Smit, C. Scale-dependent effects of grazing and topographic heterogeneity on plant species richness in a Dutch salt marsh ecosystem. Appl. Veg. Sci. 2014, 17, 615-624. [CrossRef] 